\title{
Comparison of medical students' diagnostic reasoning skills in a traditional and a problem based learning curriculum
}

\author{
Barbara Goss', Katharine Reid², Agnes Dodds², Geoff McColl² \\ ${ }^{1}$ Austin Health and Northern Health Clinical School, The University of Melbourne, Australia \\ ${ }^{2}$ Medical Education Unit, Melbourne Medical School, The University of Melbourne, Australia
}

Correspondence: Barbara Goss, Austin Health and Northern Health Clinical School, The University of Melbourne, Australia. Email: b.goss@unimelb.edu.au

\begin{abstract}
Objectives: This cross sectional study aimed to investigate the relative effectiveness of a problem based learning curriculum (PBL) and a traditional curriculum (TC) in the development of medical students' diagnostic reasoning skills.

Methods: Junior and senior clinical students $(n=431)$ at a single clinical school of the University of Melbourne selfadministered Bordage et al.'s Diagnostic Thinking Inventory (DTI) to assess diagnostic reasoning skills during transition from a TC to a PBL curriculum. Mean scores for the flexibility in thinking and memory structure sub-scales were compared for students at junior and senior clinical levels under the two curricula using multivariate analysis of variance (MANOVA).

Results: An effect of curriculum, Wilks' Lambda $=.95, \mathrm{~F}_{(2}$, 426) $=11.67, \mathrm{p}<.001, \eta_{\mathrm{p}}{ }^{2}=.05$ and level of trainee, Wilks' Lambda $=.86, \mathrm{~F}_{(2,426)}=35.00, \mathrm{p}<.001, \eta_{\mathrm{p}}{ }^{2}=.14$

was evident on DTI scores overall. Senior students on average had higher flexibility in thinking (86.7 vs. 80.9 ) and memory structure scores ( 84.8 vs. 77.9$)$ than junior students. Students in the TC had higher average flexibility in thinking (84.4 vs. 83.0) and memory structure scores (82.6 vs. 79.9) than students in the PBL curriculum.

Conclusions: These results suggest both a developmental effect and a curriculum effect in the development of diagnostic reasoning skills. Contrary to expectations, a TC appears to favour the development of diagnostic reasoning skills compared with a PBL curriculum. This unexpected finding highlights to educators the importance of monitoring student attributes during curriculum change.

Keywords: Traditional medical curriculum, PBL, diagnostic reasoning, curriculum change, diagnostic thinking inventory
\end{abstract}

\section{Introduction}

The development of effective diagnostic reasoning skills is a critical aim of all medical training. Acquisition of these skills is a complex process which is dependent upon both knowledge and clinical experience; ${ }^{1-7}$ however, the role of the curriculum in fostering diagnostic reasoning is not well understood..$^{6-9}$ In recent times, many medical schools have changed curricula from a traditional course (TC) to a problem based learning curriculum (PBL). Early proponents of PBL claimed that clinical reasoning or problemsolving skills were the most important set of abilities a doctor should possess but that these skills were not

sufficiently emphasised in traditional curriculum approaches to medical education. ${ }^{10} \mathrm{PBL}$ was seen as a way of enabling students to develop key reasoning and critical thinking skills more efficiently than traditional methods of medical education. ${ }^{11}$ The development of clinical reasoning skills characteristic of the expert clinician was cited as one of the main educational objectives of PBL. ${ }^{12}$ Nonetheless, there is little empirical evidence of the superiority of diagnostic reasoning for students trained in PBL versus TC. ${ }^{13}$

In 1999 the University of Melbourne implemented a new problem based learning course to replace the existing 
traditional course. This transition between curricula types presented the opportunity to investigate the effect of different teaching styles on the acquisition of diagnostic reasoning skills. With curriculum change comes the need to ensure that student outcome measures are maintained or improved, specifically those skills deemed critical for medical practice. In the current study therefore, medical students' diagnostic reasoning skills were assessed by means of the Diagnostic Thinking Inventory (DTI) developed by Bordage, Grant and Marsden ${ }^{14}$ to see how the skills of students in the PBL compared with those in the TC. Testing also afforded the opportunity to see how other student characteristics (e.g. gender) might relate to diagnostic reasoning ability and how students' clinical reasoning varied at different stages of the medical course.

Thus the purpose of our study was to examine the diagnostic reasoning skills of medical students at the beginning and the end of their clinical training to determine if a PBL curriculum is more effective in supporting the acquisition of these skills when compared to a TC.

\section{Context}

\section{Overview of Curricula}

The two medical courses (TC and PBL) differed in content and to some degree in student selection processes. The TC students entered the course after the final year of school and were selected by a combination of final secondary school rank (Equivalent National Tertiary Entrance Rank or ENTER) and the Undergraduate Medical Admission Test (UMAT) score. Most PBL students also entered the course directly from school using ENTER and UMAT, however approximately $25 \%$ of students had completed a prior undergraduate program and were selected by their grade point average (GPA), scores in the Graduate Australian Medical School Admissions Test (GAMSAT) and a structured interview.

TC students completed a six-year course. The first three years were university-based and focused on the enabling bioscience disciplines with little integration. Years 4-6 of the course were in a fulltime clinical setting at one of four clinical schools. Students were taught by means of a comprehensive lecture programme and clinical instruction. This was broadly structured covering semesters in general medicine and general surgery and a range of sub specialties.

The PBL was six years (12 semesters) in duration for students entering the program from secondary school and 4.5 years for students with prior tertiary qualifications. In Semesters 1-5 all students were based at the university and completed a PBL-based programme with discussion of 75 cases. The problem of the week was underpinned by an integrated biomedical science curriculum. Students also participated weekly in a clinical exposure programme which included fortnightly visits to hospitals for bed-side teaching. Semesters 6 and 7 comprised an intercalated research year for the students who entered the program from school and then all students proceeded to a clinical school for 2.5 years of fulltime clinical training. In Semesters 8 and 9, weekly PBL tutorials continued and clinical training occurred in six 6-week blocks of medical and surgical specialties (e.g. Nephrology, Urology, Endocrinology and Vascular Surgery). Semesters 10, 11 and 12 covered sub-specialties and a pre-internship.

\section{Methods}

\section{Participants}

University of Melbourne medical students undertaking their clinical training at one of the university's four clinical schools participated in the study. Between 2000 and 2005 (the period of transition from TC to $\mathrm{PBL}$ ) cohorts of students were recruited at two equivalent stages of fulltime clinical training: the end of their first 12 months - the completion of fourth year for TC and Semester 9 for PBL (junior clinical); and the end of their final year of the course - sixth year for TC and Semester 12 for PBL (senior clinical.) Participants comprised two cohorts of junior clinical and one senior clinical cohort of TC students and two cohorts of both junior and senior clinical PBL students. Table 1 shows the number of participants in each year of the study and the percentage of the total available students who participated. Response rates varied across the years of the study from a minimum of $52.4 \%$ to a maximum of $89.7 \%$.

Table 1. Number and percentage of eligible participants in each cohort $(n=431)$

\begin{tabular}{lcccc}
\hline Curriculum & Year & $\begin{array}{c}\text { No. } \\
\text { participants }\end{array}$ & $\begin{array}{c}\text { Total no. } \\
\text { students }\end{array}$ & $\begin{array}{c}\text { Participa- } \\
\text { tion } \\
\%\end{array}$ \\
\hline Traditional Curriculum & & & & \\
\hline Junior clinical (Year 4) & 2000 & 57 & 66 & 86.3 \\
& 2001 & 67 & 89 & 75.2 \\
Senior clinical (Year 6) & 2003 & 61 & 92 & 66.3 \\
\hline PBL Curriculum & & & & \\
\hline Junior clinical (Semester 9) & 2003 & 65 & 87 & 74.7 \\
& 2004 & 43 & 82 & 52.4 \\
Senior clinical (Semester 12) & 2004 & 78 & 87 & 89.7 \\
& 2005 & 60 & 86 & 69.8 \\
\hline
\end{tabular}

Demographics of participants

Of the 431 students involved in the study, 58.2\% were female and $41.8 \%$ were male. $55.9 \%$ were born in Asia, 38.7\% were born in Australia and 5.4\% were born in other locations. $43.2 \%$ had been resident in Australia for more than 18 years, 29.2\% for between 6 and 17 years and $27.6 \%$ for less than 6 years. Most (78.4\%) spoke English as their usual language at home. The characteristics of students undertaking the TC and PBL were similar. Table 2 shows the demographic characteristics of participants.

\section{Materials}

The Diagnostic Thinking Inventory (DTI) developed by Bordage, Grant and Marsden ${ }^{14}$ was used for the study as it 
has been widely used to assess diagnostic reasoning skills in different cohorts of medical students and doctors in a variety of settings. ${ }^{15-18}$ The DTI consists of 41 items. Each item comprised a stem, followed by a semantic-differential response rated on a 6-point scale. The inventory assessed two different aspects of diagnostic reasoning, (a) flexibility in thinking and (b) evidence for structure in memory. Bordage et al. defined flexibility in thinking as "the use of a variety of thinking means or processes that can be applied during the diagnostic process (p. 415)" and memory structure as "availability of knowledge, stored in memory, during the diagnostic process (p. 416)."14 Responses to the 41 items of the DTI are scored and then totalled. Total DTI scores can range from a minimum of 41 to a maximum of 246 , (flexibility in thinking 21 to 126 and structure in memory 20 to 120$)$.

Table 2. Proportion of study participants in each group with particular demographic characteristics $(n=431)^{*}$

\begin{tabular}{lcccc}
\hline \multirow{2}{*}{ Criteria } & \multicolumn{2}{c}{ Traditional Curriculum } & \multicolumn{2}{c}{ PBL Curriculum } \\
\cline { 2 - 5 } & $\begin{array}{c}\text { Junior } \\
(\mathrm{n}=124)\end{array}$ & $\begin{array}{c}\text { Senior } \\
(\mathrm{n}=61)\end{array}$ & $\begin{array}{c}\text { Junior } \\
(\mathrm{n}=108)\end{array}$ & $\begin{array}{c}\text { Senior } \\
(\mathrm{n}=138)\end{array}$ \\
\hline Gender & & & & \\
$\quad$ Female & 53.2 & 63.5 & 58.9 & 60.3 \\
$\quad$ Male & 46.8 & 36.5 & 41.1 & 39.7 \\
Years in Australia & & & & \\
$\quad$ 18 or more & 38.7 & 36.7 & 48.6 & 45.9 \\
$\quad$ 6-17 & 29.8 & 23.3 & 24.8 & 34.8 \\
$\quad$ Less than 6 & 31.5 & 40.0 & 26.7 & 19.3 \\
Country of birth & & & & \\
$\quad$ Australia & 33.1 & 34.4 & 45.3 & 40.7 \\
$\quad$ Asia & 59.7 & 62.3 & 50.0 & 54.1 \\
$\quad$ Other & 7.3 & 3.3 & 4.7 & 5.2 \\
English spoken at home & & & & \\
$\quad$ Yes & 74.0 & 81.7 & 82.9 & 77.6 \\
$\quad$ No & 26.0 & 18.3 & 17.1 & 22.4 \\
\hline
\end{tabular}

* Proportions in Table 1 are based on valid values (missing values $n=12$ for gender, $n=7$ for years in Australia, $n=5$ for country of birth and $n=9$ for English spoken at home)

\section{Procedure}

In this cross sectional study, participants were invited to complete the DTI as part of routine evaluations conducted in a whole class lecture theatre setting at the end of clinical programs. Ethics approval was not formally sought as the data was collected as part of routine quality assurance and the measure assessed an aspect of skill acquisition similar to other assessments of students' skills. Student participation was voluntary and student responses were anonymous.

\section{Data Analysis}

The purpose of the analysis was to determine if there was variation in diagnostic reasoning ability between the different groups of students assessed in the study. A total DTI score was determined for each student as well as flexibility in thinking and memory structure sub-scales. A multivariate analysis of variance (MANOVA) was conducted with clinical level (junior or senior) and curriculum type (TC or $\mathrm{PBL}$ ) as independent variables and the scores on the flexibility in thinking and memory structure scales of the DTI as dependent variables. A second MANOVA explored variation in scores on the diagnostic reasoning sub-scales as a function of student gender and the length of time students had been resident in Australia (18 or more years, 6-17 years, less than 6 years). All analyses were conducted using PASW Statistics for Windows Release 18.0 (SPSS Inc., Chicago, IL, USA).

\section{Results}

\section{Internal consistency of scales}

Measures of internal consistency were calculated using PASW 18.0 reliability analysis by requesting Cronbach's alpha for the scales, the corrected item-total correlations and Cronbach's alpha if the item is deleted. The internal consistency of the scale overall (Cronbach's Alpha .86) and for the 21 items comprising the flexibility in thinking scale (Cronbach's Alpha .74) and the 20 items comprising the memory structure scale (Cronbach's Alpha .77) are comparable with those reported by Bordage et al. (overall $.83 ; .72$ and .74 for the flexibility in thinking and memory structure scales respectively). ${ }^{14}$ It should be noted that three items with very low corrected item-total correlations were identified. Item 11 (Clarification before further data acquisition), Item 14 (Diagnostic error: lack of knowledge or inability to retrieve existing knowledge) and item 25 (Specific enquiry) all had close to zero corrected item-total correlations $(\mathrm{r}=.09, \mathrm{r}=.02$ and $\mathrm{r}=-.01$ respectively). These items were retained in the analyses for comparability with Bordage et al.'s original scale and because dropping these items improved the scale's internal consistency only marginally. However, the results suggest that these items might have limited use as discriminating items in the inventory. In particular, Bordage et al. identified Item 25 as a potentially ambiguous item, though the authors decided to retain the item in the final scale. ${ }^{14}$

The mean total DTI score for all junior clinical students including students from both curricula was 158.8 (SD = $18.5)$ and the mean total score for all senior clinical students was $171.5(\mathrm{SD}=18.8$.) The mean total score recorded for junior clinical students in this study is comparable to that reported for third-year medical students by Bordage et al. $(\mathrm{M}=158.3)$ and the mean total score for senior clinical students was similar to that of Senior House Officers $(\mathrm{M}=$ 170.1). ${ }^{14}$

Data from students in cohorts from the PBL and TC at the same level were pooled to optimise statistical strength. The average scores were very similar for same level cohorts, (junior clinical TC: flexibility in thinking 82.7, 81.4; memory structure 79.8, 79.0; total DTI 162.5, 160.4. Junior clinical PBL: flexibility in thinking 80.0, 79.2; memory structure 76.5, 75.7; total DTI 156.4, 154.9. Senior clinical PBL: flexibility in thinking $86.3,84.8$; memory structure 83.9, 81.4; total DTI 170.2, 166.2). The pooled DTI scale scores are shown in Table 3. 
Table 3. Means, standard deviations and 95\% confidence intervals $(\mathrm{Cl})$ for the diagnostic reasoning scales as a function of group $(n=431)^{*}$

\begin{tabular}{|c|c|c|c|c|c|}
\hline & & & & $\% \mathrm{Cl}$ & \\
\hline & M & SD & $\begin{array}{l}\text { Lower } \\
\text { Bound }\end{array}$ & $\begin{array}{l}\text { Upper } \\
\text { Bound }\end{array}$ & $\mathrm{F}$ \\
\hline Flexibility in Thinking & & & & & \\
\hline Traditional Curriculum $(n=185)$ & 84.4 & 11.1 & 82.8 & 86.0 & $8.09^{-*}$ \\
\hline PBL Curriculum $(n=246)$ & 83.0 & 10.3 & 81.7 & 84.3 & \\
\hline Junior Clinical $(n=232)$ & 80.9 & 10.5 & 79.6 & 82.3 & $40.20^{* *}$ \\
\hline Senior Clinical $(n=199)$ & 86.7 & 10.0 & 85.3 & 88.1 & \\
\hline Memory Structure & & & & & \\
\hline Traditional Curriculum $(n=185)$ & 82.6 & 10.9 & 81.0 & 84.2 & $23.06^{\dagger}$ \\
\hline PBL Curriculum $(n=246)$ & 79.9 & 10.3 & 78.6 & 81.2 & \\
\hline Junior Clinical $(n=232)$ & 77.9 & 10.0 & 76.6 & 79.2 & $69.31^{\ddagger}$ \\
\hline Senior Clinical $(n=199)$ & 84.8 & 10.2 & 83.4 & 86.2 & \\
\hline
\end{tabular}

Analysis of group differences in diagnostic reasoning ability

For all reported analyses, effect size is reported using partial eta squared $\left(\eta_{\mathrm{p}}{ }^{2}\right)$ where $.01, .06$ and .14 are considered small, medium and large effects. ${ }^{19}$ Overall, there was a significant effect of curriculum, Wilks' Lambda $=.95, \mathrm{~F}_{(2,426)}$ $=11.67, \mathrm{p}<.001, \eta_{\mathrm{p}}{ }^{2}=.05$ and for the level of trainee, Wilks' Lambda $=.86, \mathrm{~F}_{(2,426)}=35.00, \mathrm{p}<.001, \eta_{\mathrm{p}}{ }^{2}=.14$. There was, however, no interaction between clinical level and curriculum type, Wilks' Lambda $=.99, \mathrm{~F}_{(2,426)}=1.58, \mathrm{p}=.208$.

Tests of between subjects effects indicated that senior clinical students evidenced higher diagnostic reasoning scores than junior clinical students on the flexibility in thinking scale (senior: $\mathrm{M}=86.7, \mathrm{SD}=10.0,95 \% \mathrm{CI}=85.3-$ 88.1, junior: $\mathrm{M}=80.9, \mathrm{SD}=10.5,95 \% \mathrm{CI}=79.6-82.3), \mathrm{F}_{(1}$, 427) $=40.20, \mathrm{p}<.001, \eta_{\mathrm{p}}{ }^{2}=.09$ and also on the memory structure scale (senior: $\mathrm{M}=84.8, \mathrm{SD}=10.2,95 \% \mathrm{CI}=83.4-$ 86.2, junior: $\mathrm{M}=77.9, \mathrm{SD}=10.0,95 \% \mathrm{CI}=76.6-79.2), \mathrm{F}_{(1}$, 427) $=69.31, \mathrm{p}<.001, \eta_{\mathrm{p}}{ }^{2}=.14$. There was also an effect of the curriculum, with students in the TC recording higher diagnostic reasoning scores than students in the PBL curriculum for both the flexibility in thinking scale (TC: M $=84.4, \mathrm{SD}=11.1,95 \% \mathrm{CI}=82.8-86.0, \mathrm{PBL}: \mathrm{M}=83.0, \mathrm{SD}=$ $10.3,95 \% \mathrm{CI}=81.7-84.3), \mathrm{F}_{(1,427)}=8.09, \mathrm{p}=.005, \eta_{\mathrm{p}}{ }^{2}=.02$ and the memory structure scale (TC: $\mathrm{M}=82.6, \mathrm{SD}=10.9$, 95\% CI $=81.0-84.2$, PBL: $\mathrm{M}=79.9, \mathrm{SD}=10.3,95 \% \mathrm{CI}=$ $78.6-81.2), \mathrm{F}_{(1,427)}=23.06, \mathrm{p}<.001, \eta_{\mathrm{p}}{ }^{2}=.05$.

\section{Analysis of differences in diagnostic reasoning ability} by gender and years of residence in Australia

Table 4 shows the mean scores for the flexibility in thinking and memory structure scales as a function of gender and years of residence in Australia. A MANOVA was conducted with gender and years in Australia (18 or more, 6-17, less than 6) as independent variables and scores on the flexibility in thinking and memory structure scales as dependent variables. In order to constrain the number of independent 90 variables in the analysis, country of birth was not included because it was strongly related to years of residence in Australia. That is, Australian born students had almost always been resident in Australia more than 18 years (95.2\%) and students born in Asia had almost always been resident less than 18 years (91.1\%). Similarly, speaking English at home was not included because most students resident in Australia more than 18 years (97.8\%) spoke English at home.

Multivariate tests indicated that overall there was a significant effect of gender, Wilks' Lambda $=.98, \mathrm{~F}_{(2,408)}=$ $4.25, \mathrm{p}=.015, \eta_{\mathrm{p}}{ }^{2}=.02$, and of years of residence in Australia, Wilks' Lambda $=.97, \mathrm{~F}_{(4,816)}=3.66, \mathrm{p}=.006, \eta_{\mathrm{p}}{ }^{2}=.02$. Tests of between subjects effects indicated that female and male students did not differ on the flexibility in thinking scale, $\mathrm{F}_{(1,409)}=.19, \mathrm{p}=.661$, however, females $(\mathrm{M}=81.9$, SD $=10.7,95 \% \mathrm{CI}=80.6-83.3)$ had higher average scores than males $(\mathrm{M}=79.3, \mathrm{SD}=10.1,95 \% \mathrm{CI}=77.7-80.8)$ for the memory structure scale, $\mathrm{F}_{(1,409)}=5.46, \mathrm{p}=.020, \eta_{\mathrm{p}}{ }^{2}=.01$. There was variation in diagnostic reasoning scores according to the number of years resident in Australia, $\mathrm{F}_{(2,409)}=$ 5.92, $\mathrm{p}=.003, \eta_{\mathrm{p}}{ }^{2}=.03$. Tukey post hoc comparisons indicated that students who had been resident in Australia for fewer than six years had lower flexibility in thinking scores $(\mathrm{M}=80.4, \mathrm{SD}=10.5,95 \% \mathrm{CI}=78.5-82.4)$ than students who had been in resident in Australia for between six and seventeen years $(\mathrm{M}=84.2, \mathrm{SD}=10.0,95 \% \mathrm{CI}=$ $82.4-85.9)(\mathrm{p}=.021)$, or for 18 years or more $(\mathrm{M}=85.1, \mathrm{SD}$ $=10.7,95 \% \mathrm{CI}=83.6-86.7)(\mathrm{p}=.001)$. Memory structure scores did not vary with the number of years resident in Australia, $\mathrm{F}_{(2,409)}=.81, \mathrm{p}=.447$. There was also no interaction between gender and number of years resident in Australia, $\mathrm{F}_{(4,818)}=1.06, \mathrm{p}=.373$.

Table 4. Means, standard deviations and 95\% confidence intervals $(\mathrm{Cl})$ for the diagnostic reasoning scales as a function of gender and years of residence in Australia $(n=431)^{\star}$

\begin{tabular}{|c|c|c|c|c|c|}
\hline & \multirow[b]{2}{*}{ M } & \multirow[b]{2}{*}{$S D$} & \multicolumn{2}{|c|}{$95 \% \mathrm{Cl}$} & \multirow[b]{2}{*}{$\mathrm{F}$} \\
\hline & & & $\begin{array}{l}\text { Lower } \\
\text { Bound }\end{array}$ & $\begin{array}{l}\text { Upper } \\
\text { Bound }\end{array}$ & \\
\hline \multicolumn{6}{|l|}{ Flexibility in Thinking } \\
\hline Female $(n=244)$ & 84.0 & 10.9 & 82.6 & 85.3 & .19 \\
\hline Male $(n=175)$ & 82.8 & 10.4 & 81.2 & 84.3 & \\
\hline Resident 18 or more years $(n=183$ ) & 85.1 & 10.7 & 83.6 & 86.7 & $5.92^{\dagger}$ \\
\hline Resident $6-17$ years $(n=124)$ & 84.2 & 10.0 & 82.4 & 85.9 & \\
\hline Resident $<6$ years $(n=117)$ & 80.4 & 10.5 & 78.5 & 82.4 & \\
\hline \multicolumn{6}{|l|}{ Memory Structure } \\
\hline Female $(n=244)$ & 81.9 & 10.7 & 80.6 & 83.3 & $5.46^{\ddagger}$ \\
\hline Male $(n=175)$ & 79.3 & 10.1 & 77.7 & 80.8 & \\
\hline Resident 18 or more years $(n=183$ ) & 82.0 & 11.4 & 80.3 & 83.7 & .81 \\
\hline Resident $6-17$ years $(n=124)$ & 80.9 & 10.1 & 79.1 & 82.7 & \\
\hline Resident $<6$ years $(n=117)$ & 79.7 & 9.3 & 78.0 & 81.4 & \\
\hline
\end{tabular}

* Comparisons of mean DTI scores were conducted using MANOVA. The numbers reported in Table 4 do not add to the total number of participants due to missing data. reported in Table 4 do not add to the total number of participants due to missing data.
t $F_{(2,409)}=5.92, p=.003, \eta_{p}{ }^{2}=.03$ (7 students did not report their years resident in $\dagger F_{(2,409)}=5.92, p=.003, \eta_{p}^{2}=.03$ (7 students did not report their years
Australia)
$\ddagger F(1,409)=5.46, p=.020, \eta_{\mathrm{p}}{ }^{2}=.01$ (12 students did not report their gender) 


\section{Discussion}

The results of this study demonstrated that students completing a TC and a PBL both have a significant improvement in diagnostic reasoning skill, as measured by the DTI, from early in clinical training to the end of the course. This is consistent with the findings of other investigators who have measured the diagnostic reasoning skills of students and doctors using the DTI. ${ }^{14,15,18,20,21}$ The second finding of our study was that students completing the TC had higher DTI scores than those completing the PBL. This was apparent both at the end of the first year of clinical training and at the end of the course. It was anticipated that the new PBL course would give students a stronger grounding in diagnostic reasoning which would better prepare them for the clinical setting. It was therefore surprising that in our study TC students displayed superior reasoning skills to students from the PBL course.

There are a number of differences in the curricula that may explain the pattern of findings in the current study. Both the TC and PBL were six years in duration for students entering the program from secondary school however the PBL included a year of research (Semesters 6 and 7) prior to the first fulltime clinical year (Semesters 8 and 9). This followed five semesters which included weekly discussion of clinical problems and patient-centred teaching in hospitals. Neither a research year nor early clinical learning were components of the TC course. It is possible that the yearlong break in the PBL significantly interfered with recall of previous clinical experience and learning from clinical cases thereby compromising the development of diagnostic reasoning skills.

Another difference between the TC and PBL was the structure of clinical experience in the fulltime clinical environment. In the TC, the students' terms were broadbased with exposure to a wide range of clinical problems while in the PBL most clinical training was in systems-based blocks with focus on a narrow range of clinical material in each block. It may be that this different experience of clinical learning affected the development of diagnostic reasoning skills and contributed to the differences found in DTI scores. In a review paper of diagnostic reasoning, Eva noted that mixed practice where students saw cases of multiple categories mixed together was pedagogically superior to 'blocked' practice. ${ }^{4}$ Sefton, commenting on students' acquisition of clinical reasoning skills, noted that students in PBL curricula may be inhibited from freeranging exploration of issues because of problems being collated into blocks of material. This criticism relates mostly to the early years with a less structured environment encouraging broader thinking. ${ }^{7}$

The time spent in clinical training was also different in the two curricula. In the TC clinical training was three years and in the PBL two and a half years. A number of researchers have concluded that clinical experience is an important aspect in the development of diagnostic reasoning skills to expert level with skills improving in relation to the number of clinical encounters. ${ }^{1,2,4,22,23}$ Thus the change in the course to a reduction in fulltime clinical experience from three to two and a half years may be a significant factor in the difference found between senior clinical groups in this study, however, this does not explain the differences identified at the junior level.

The difference in diagnostic reasoning scores at the junior clinical level was most marked in the memory structure component of the DTI. In a study by Patel et al examining the link between basic science and diagnostic reasoning, the authors concluded that students' diagnostic reasoning may benefit from a strong biomedical knowledge foundation which is not necessarily embedded in PBL. ${ }^{6}$ Indeed, Patel et al postulated that confusion may arise when students are taught clinical and biomedical sciences together (as in PBL), which may result in the formation of two incomplete and ill-formed knowledge domains, whereas the separation of science and clinical instruction, as in TC, may help longterm in diagnostic reasoning and understanding. ${ }^{8}$

Few other investigators have assessed diagnostic reasoning skills of students in different curricula. Sobral, in a study from Brazil, used the DTI to compare students' ability from traditional and integrated PBL pre-clinical streams after 22 weeks of clinical training. ${ }^{17}$ There was no significant difference in total DTI scores, but in contrast to the current study, the PBL students had significantly higher scores than the TC students for the memory structure component. Groves, in a study in Queensland, found no difference in DTI scores between students from a traditional course compared with PBL but this study included only a small cohort of 24 final year TC students. ${ }^{24}$ Groves speculated that the failure to detect superior reasoning skills in students in a four-year PBL course compared with a six-year conventional course might be due to the reduction in course length. Using a different approach, Patel compared the effects of TC and PBL on reasoning strategies by assessing students' responses to clinical problems. ${ }^{8}$ This study found that a PBL did not confer better diagnostic reasoning skills in students and in keeping with our findings TC students were noted to use reasoning strategies more characteristic of experts than students from a PBL curriculum.

We also found that gender had a significant influence on some aspects of student reasoning performance. Average scores for the memory structure component of the DTI were significantly higher in female medical students compared with males. This finding was different from some investigators who found no gender difference in DTI scores. ${ }^{17,20}$ However, Groves reported significantly higher clinical reasoning scores in females when assessed on a different measure - Clinical Reasoning Problems (CRP). ${ }^{15}$

Another important finding of the study was that time spent in Australia appeared to affect diagnostic reasoning 
skills. Students who had spent less than six years in the country had significantly lower flexibility of thinking scores than other students at both a junior and senior clinical level. It may be that those students who do not have English as their first language have some difficulty with the language of the DTI or the skills of diagnostic reasoning in a foreign language.

\section{Limitations of the study}

There are several possible limitations to this study to consider. Only one of four clinical schools of the University of Melbourne was involved so the results are not necessarily generalisable as characteristics of both the teaching and students may differ. A single measure was used to assess clinical reasoning skills and this was a self-reported questionnaire. Whilst this tool has been widely used and our results were consistent with other studies showing increased DTI scores over time in clinical training - and consistent with Bordage's findings, in future consideration could be given to using a second measure of clinical reasoning and including an observed rating of skills. This is important because a broader assessment, which includes measures that do not only rely on self-report, is likely to provide a more accurate picture of diagnostic reasoning ability. There was only one opportunity for students to complete the questionnaire at an end of year evaluation session. Response rates varied but in most cohorts this was close to $70 \%$ or above. It is not possible to know whether the nonresponders differed in any way from the responders, however as reported, the DTI scores from the same level cohorts were very similar.

\section{Conclusions}

This study demonstrated a clear difference in diagnostic reasoning skills between junior and senior clinical students providing evidence that there is progression from novice to more expert skills during clinical training. Of interest was the finding that at both junior and senior levels students in a TC had superior diagnostic reasoning skills compared with students in a PBL. This is unexpected, given the emphasis in the PBL on enquiry-based learning and early clinical encounters. It is possible that this difference relates to both a reduction in overall time for clinical experience in the new course, as well as the break prior to commencement of fulltime clinical training resulting in loss of previously acquired skills. It is also possible that having a wellestablished scientific knowledge base and a programme of broad-based clinical instruction, as in the traditional course, enhances the development of clinical reasoning skills.

With medical schools throughout the world undertaking curricular change it is important to monitor the effects of these changes on medical graduates' skills. The University of Melbourne has recently introduced another curricu- lum change with a move to a post-graduate medicine model. All students entering the new course are required to have a strong foundation in biomedical science and the course includes a three-year clinical component following directly on from one pre-clinical year. It will be of considerable interest to investigate the clinical reasoning of students in the graduate course compared to that of students taught under the two previous curricula.

\section{Acknowledgements}

The authors wish to thank Professor Georges Bordage for permission to use the Diagnostic Thinking Inventory and the students from the Austin Health and Northern Health Clinical School of the University of Melbourne who participated in this study.

\section{Conflict of Interest}

The authors declare that they have no conflict of interest.

\section{References}

1. Bowen JL. Educational strategies to promote clinical diagnostic reasoning. N Engl J Med. 2006;355(21):2217-25.

2. de Bruin ABH, Schmidt HG, Rikers RMJP. The role of basic science knowledge and clinical knowledge in diagnostic reasoning: a structural equation modeling approach. Acad Med. 2005;80(8):765-73.

3. Elstein AS, Schwarz A. Clinical problem solving and diagnostic decision making: selective review of the cognitive literature. BMJ. 2002;324(7339):729-32.

4. Eva KW. What every teacher needs to know about clinical reasoning. Med Educ. 2004;39(1):98-106.

5. Norman G. Building on experience-the development of clinical reasoning. N Engl J Med. 2006;355:2251-52.

6. Patel VL, Evans DA, Groen GJ. Reconciling basic science and clinical reasoning. Teach Learn Med. 1989;1(3):116-21.

7. Sefton A, Gordon J, Field M. Teaching clinical reasoning to medical students. In: Higgs J, Jones M, editors. Clinical reasoning in the health professions. 2nd Ed. Oxford: Butterworth-Heinemann; 2000.

8. Patel VL, Groen GJ, Norman G. Effects of conventional and problem-based medical curricula on problem solving. Acad Med. 1991;66:380-89.

9. Schmidt HG, Machiels-Bongaerts $M$, Hermans $H$, ten Cate TJ, Venekamp R, Boshuizan HPA. The development of diagnostic competence: comparison of a problem-based, an integrated, and a conventional medical curriculum. Acad Med. 1996;71:658-64.

10. Barrows HS, Tamblyn RM. Problem-based learning: an approach to medical education. New York: Springer Publishing; 1980.

11. Walton HJ, Matthews M. Essentials of problem based learning. Med Educ. 1989;23(6):542-58.

12. Barrows HS. Problem-based, self-directed learning. JAMA. 1983;250(22):3077-80. 
13. Colliver JA. Effectiveness of problem-based learning curricula: research and theory. Acad Med. 2000;75:259-66.

14. Bordage G, Grant J, Marsden P. Quantitative assessment of diagnostic ability. Med Educ. 1990;24:413-25.

15. Groves M, O'Rourke P, Alexander H. The association between student characteristics and the development of clinical reasoning in a graduate-entry, PBL medical programme. Med Teach. 2003;25:626-31.

16. Round A. Teaching clinical reasoning-a preliminary controlled study. Med Educ. 1999;33:480-83.

17. Sobral D. Diagnostic ability of medical students in relation to their learning characteristics and preclinical background. Med Educ. 1995;29:278-82.

18. Rahayu GR, McAleer S. Clinical reasoning of Indonesian medical students as measured by diagnostic thinking inventory. South East Asian Journal of Medical Education. 2008;2:42-7.
19. Cohen J. Statistical power analysis for the behavioral sciences: New York: Academic Press; 1977.

20. Groves MA, Gordon J, Ryan G. Entry tests for graduate medical programs: is it time to re-think? Med J Aust. 2007;186:120-23.

21. Jerant AF, Azari R. Validity of scores generated by a web-based multimedia simulated patient case software: a pilot study. Acad Med. 2004;79:805-11.

22. Norman G, Young M, Brooks L. Non analytical models of clinical reasoning: the role of experience. Med Educ. 2007;41:1140-45.

23. Schmidt HG, Norman G, Boshuizan HPA. A cognitive perspective on medical expertise: theory and implications. Acad Med. 1990;65:611-21.

24. Groves M. The clinical reasoning process: a study of its development in medical students, unpublished $\mathrm{PhD}$. Brisbane: The University of Queensland; 2002. 